\title{
PENGARUH ION LOGAM CU(II) TERHADAP PERSEN EKSTRAKSI ION Pb(II) MENGGUNAKAN TEKNIK EMULSI MEMBRAN CAIR
}

\author{
Effect of $\mathrm{Cu}$ (II) Ion towards Percent Extraction of $\mathrm{Pb}$ (II) using Emulsion \\ Liquid Membrane Technique
}

\author{
*Dwi Ardi Irawati, Baharuddin Hamzah, dan Nurdin \\ Pendidikan Kimia/FKIP - Universitas Tadulako, Palu - Indonesia 94118 \\ Received 07 September 2016, Revised 07 October 2016, Accepted 08 November 2016
}

\begin{abstract}
Utilization of information technology in particular a $Q R$ Code in education is still lacking. Therefore This study aimed to determine effect of $C u(I I)$ ion toward percent extraction of $\mathrm{Pb}(\mathrm{II})$ ion using emulsion liquid membrane technique. Variation concentrations of $\mathrm{Cu}(I I)$ added were 0, 50, 100, 150, 200 and $250 \mathrm{ppm}$ with the initial concentration of Pb(II) was $245 \mathrm{ppm}$. This extraction used benzoyl acetone as a chelating agent. The extraction results were measured by Spectrodirect. The results showed that percent extraction of $\mathrm{Pb}$ (II) ion prior addition of Cu(II) ion was $99.09 \%$, but after addition of $\mathrm{Cu}(\mathrm{II})$ to a concentration up to $250 \mathrm{ppm}$, the percent extraction of Pb(II) ions turned to decrease by $97.92 \%$.
\end{abstract}

Keywords: Extraction, emulsion liquid membrane, concentration of $\mathrm{Cu}(\mathrm{II})$,percent extraction of $\mathrm{Pb}(\mathrm{II})$ ion

\section{Pendahuluan}

Semakin berkembangnya penggunaan bahan industri yang menghasilkan limbah cair yang mengandung residu organik dan anorganik akan mengakibatkan potensi atau dampak negatif bagi lingkungan dan kesehatan manusia, maka menjadi solusi yang wajib untuk mengurangi atau menghapuskan polutan. Logam $\mathrm{Pb}$ dan $\mathrm{Cu}$ yang dapat berada di dalam badan perairan secara alamiah dan dapat berdampak bagi aktivitas manusia. Konsumsi $\mathrm{Cu}$ dan $\mathrm{Pb}$ dalam jumlah yang besar dapat menyebabkan $\mathrm{Cu}$ dan $\mathrm{Pb}$ bersifat toksik dan menimbulkan gejala-gejala yang akut(Deswati, dkk., 2011). Sehingga untuk mengurangi dampak tersebut, beberapa teknik yang telah berkembang digunakan oleh sebagian orang yang telah didukung oleh teknologi.

Ekstraksi pelarut adalah teknik yang umum digunakan, tetapi membutuhkan sejumlah besar pelarut organik dan ekstraktan logam dan menjadi tidak efisien ketika konsentrasi ion logam dalam aliran limbah rendah (Mohamed \& Ibrahim, 2012). Ekstraksi membran cair

\section{*Correspondence:}

Dwi Ardi

Program Studi Pendidikan Kimia, Fakultas Keguruan dan

Ilmu Pendidikan, Universitas Tadulako

email:dwiardi_irawati@yahoo.com

Published by Universitas Tadulako 2016 merupakan suatu metode yang dapat digunakan dalam proses pemisahan, pemurnian, ekstraksi, atau proses pungut ulang (recovery) material yang diinginkan. Metode ini merupakan pengembangan dari metode ekstraksi untuk pemisahan dan pemurnian logam dengan menggabungkan ekstraksi dan reekstraksi (stripping) dalam satu tahap(Prayitno \& Budiyono, 2001).

Emulsi membran cair dalam berbagaiformulasi menjadikan teknik ini sebuah proses yang sangat berguna untuk aplikasi yang berbeda(Alaguraj dkk., 2009). Ada dua jenis tipe emulsi yaitu emulsi air dalam minyak (w/o) dan emulsi minyak dalam air $(\mathrm{o} / \mathrm{w})$ (Fitriya, 2005). Untuk menjaga kestabilan emulsi selama proses pemisahan, maka ke dalam membran ditambahkan zat aktif permukaan (surfaktan) yang umumnya berfungsi untuk menurunkan tegangan permukaan antara tetesan fasa terdispersi dan rasa umpan(Rusdianasari \& Buchari, 2001). Parameter yang terkandung dalam surfaktan yaitu hydrophile lypophile balance (HLB). Penentuan jenis minyak atau senyawa organik berdasarkan nilai HLB butuhnya memungkinkan kita memilih surfaktan atau campuran surfaktan yang memberikan nilai HLB yang sesuai. Jadi, penggunaan surfaktan 
dengan nilai HLB yang sesuai dengan nilai HLB butuh minyak yang digunakan akan menghasilkan emulsi yang stabil(Hamzah, dkk., 2013).

Beberapa penelitian telah dilakukan sebelumnya yaitu oleh Alam (2014)tentang penentuan kondisi optimum ekstraksi ion $\mathrm{Pb}(\mathrm{II})$ menggunakan teknik emulsi membran cair yang memberikan hasil perbandingan antara volume emulsi dan volume fasa ekstrnal yang menghasilkan persen ekstraksi maksimum adalah 1:6 dan konsentrasi larutan ion $\mathrm{Pb}(\mathrm{II})$ yang menghasilkan persen ekstraksi maksimum yaitu pada konsentrasi 220 ppm. Selanjutnya Astuti (2014)melakukan penelitian tentang "variasi perbandingan fasa membran dan fasa internal serta konsentrasi $\mathrm{HNO}_{3}$ dalam fasa internal terhadap ekstraksi ion $\mathrm{Pb}$ (II) menggunakan teknik emulsi membran cair. Diperoleh hasil yaitu persen ekstraksi terbesar pada ekstraksi $\mathrm{Pb}(\mathrm{II})$ diperoleh pada perbandingan 2:3 dengan persen ekstraksi sebesar 80,67\% dan menggunakan $\mathrm{HNO}_{3}$ dengan konsentrasi $3 \mathrm{M}$ diperoleh persen ekstraksi $\mathrm{Pb}$ (II) sebesar 84,45\%. Perbandingan antara volume fasa membrane dan fasa internal adalah 2:3 diperoleh persen ekstraksi $\mathrm{Pb}(\mathrm{II})$ sebesar $80,67 \%$. Kemudian Masgul (2014) melakukan penelitian tentang "variasi konsentrasi Span-80 dan pH fasa eksternal pada ekstraksi ion $\mathrm{Pb}(\mathrm{II})$ dengan metode emulsi membran cair". Diperoleh hasil yaitu penggunaan Span-80 dengan konsentrasi $3 \%$ merupakan kondisi optimum $\mathrm{Pb}$ (II) yang menghasilkan persen ekstraksi sebesar $68,06 \%$ dan menggunakan $\mathrm{pH}$ pada fasa ekternal yang menghasilkan persen ekstraksi ekstraksi maksimum $\mathrm{Pb}(\mathrm{II})$ yaitu pada $\mathrm{pH} 2$ dengan persen ekstraksi sebesar 74,36\%. Telah dilakukan penelitian sebelumnya, tentang pengaruh ion logam menggunakan teknik emulsi membran cair. Namun, saat ini belum ada penelitian tentang pengaruh penambahan logam $\mathrm{Cu}$ (II) terhadap persen ekstraksi ion $\mathrm{Pb}(\mathrm{II})$ menggunakan teknik yang sama yaitu emulsi membran cair.

Keberadaan logam $\mathrm{Pb}$ pada lingkungan yang berasal dari pembuangan air limbah industri kimia seringkali ditemukan bahan pencemar logam berat lainnya antara lain merkuri $(\mathrm{Hg})$, arsenik $(\mathrm{As})$, kadmium $(\mathrm{Cd})$, kromium $(\mathrm{Cr})$, nikel $(\mathrm{Ni})$, kuprum $(\mathrm{Cu})$ dan $\mathrm{Pb}(\mathrm{Pb})$ (Herlina \& Wulandari, 2012). Hal ini juga diketahui bahwalogam berat memiliki afinitas untuk bagian yang berbeda dari tanah(Gzar dkk., 2014). Yang kemungkinan logam-logam tersebut dapat mempengaruhi proses ek straksi dari $\mathrm{Pb}(\mathrm{II})$. Tulisan ini bertujuan untuk mengetahui tentang pengaruh ion logam $\mathrm{Cu}$ (II) terhadap persen ekstraksi ion $\mathrm{Pb}$ (II) menggunakan teknik emulsi membran cair

\section{Metode}

Alat yang digunakan pada penelitian ini yaitu spektrofotometer spektrodirect (Lovibond), $\mathrm{pH}$ meter, gelas kimia, gelas ukur, labu ukur $1000 \mathrm{~mL}$, neraca analitik, spatula, batang pengaduk, magnetic strirer, pipet tetes, pipet volume, karet penghisap, statif dan klem, corong pisah, botol semprot,Cimarec Stiring dan Hot Plates.

Bahan-bahan yang digunakan pada penelitian ini yaitu benzoil aseton (Merck Schuchardt OHG), SPAN-80 (Merck Schuchardt OHG), paraffin cair (Merck $\mathrm{kGaA}), \mathrm{HNO}_{3} 3 \mathrm{M}$ dan 0,01 M (Smart-lab indonesia), $\mathrm{Pb}\left(\mathrm{NO}_{3}\right)_{2}$ (Aldrich), aquades, dan larutan $\mathrm{Cu}$ (II) (Ajax chemicals).

\section{Prosedur Penelitian}

Pembuatan Larutan Pb(II) dengan konsentrasi 500 ppm dalam $1000 \mathrm{~mL}$

Menimbang $\mathrm{Pb}(\mathrm{II})$ nitrat sebanyak 0,799 gram melarutkan dalam gelas kimia. Kemudian memasukkan ke dalam labu ukur $1000 \mathrm{~mL}$ dan menambahkan aquades hingga mencapai tanda batas dan menambahkan larutan $\mathrm{HNO}_{3}$ 0,01 M sebanyak 2 tetes.

\section{Proses Ekstraksi dengan Teknik Emulsi Membran Cair}

Emulsi dibuat dengan cara mencampurkan fasa membran (benzoil aseton $0,02 \mathrm{M}$, parafin cair dan span-80 3\%) dengan fasa internal yang mengandung larutan $\mathrm{HNO}_{3} 3 \mathrm{M}$ (Astuti, 2014) (diaduk dengan skala 10 selama 10 menit). Perbandingan volume fasa membran sebanyak $12 \mathrm{~mL}$ dan fasa internal sebanyak 18 mL dengan perbandingan yaitu 2:3 (Astuti, 2014). Pencampuran kedua larutan tersebut menghasilkan sebanyak $30 \mathrm{~mL}$ emulsi yang terbentuk yang kemudian dicampurkan dengan campuran larutan ion $\mathrm{Pb}$ (II) dengan konsentrasi500 ppm(Alam, 2014)sebanyak $90 \mathrm{mLd}$ engan $\mathrm{pH}$ 2,0(Masgul, 2014)dan 90 mL larutan $\mathrm{Cu}$ (II) dengan variasi konsentrasi yaitu 0, 100, 200, 300, 400, dan 500 ppm. Proses ekstraksi ini dilakukan dengan kecepatan pengadukkan pada skala 5 selama 15 menit. Setelah proses ekstraksi, hasil ekstraksi dipindahkan kedalam corong pisah untukdipisahkan antara fasa eksternal dengan emulsi.

Besar persen ekstraksi ion $\mathrm{Pb}(\mathrm{II})$ yang 
dapat terekstrak ke dalam fasa membran (parafin cair), dapat dilakukan pengukuran dengan menggunakan alat Spectrofotometer Spectrodirectuntuk mengetahui banyaknya ion timbal(II) yang masih tersisa dalam fasa eksternal. Maka, pada penelitian ini digunakan persamaan dari Chang, dkk., (2009)yang dimodifikasi untuk menghitung persen $\%=\frac{[\mathrm{Pb}]_{\text {awal }}-[\mathrm{Pb}]_{\text {akhir }}}{[\mathrm{Pb}]_{\text {awal }}} \times 100 \%$

Dimana, \% E = persen ekstraksi; $[\mathrm{Pb}]$ awal $=$ konsentrasi awal ion timbal(II) dalam larutan (fasa eksternal); $\mathrm{Pb}]$ akhir = konsentrasi akhir ion timbal(II) dalam larutan (fasa eksternal) setelah ekstraksi(Chang, dkk., 2009)

\section{Hasil dan Pembahasan}

Pengaruh Penambahan Logam Cu(II) Terhadap Persen Ekstraksi Ion Pb(II)

Data hasil analisis Pengaruh Penambahan Logam Cu(II) Terhadap Persen Ekstraksi Ion $\mathrm{Pb}$ (II) dafrabellihattand ThatheAlnalis is pengaruh penambahan logam $\mathrm{Cu}$ (II) terhadap persen ekstraksi ion $\mathrm{Pb}(\mathrm{II})$

\begin{tabular}{cccccc}
\hline No & $\begin{array}{l}\text { Konsentrasi } \\
\begin{array}{l}\text { Cu(II) yang } \\
\text { ditambahkan }\end{array}\end{array}$ & $\begin{array}{l}\text { Konsentrasi } \\
\text { Pb(II) mula- } \\
\text { mula (ppm) } \\
\text { Kumsentrasi }\end{array}$ & $\begin{array}{l}\text { Kon ekstraksi } \\
\text { Pb(II) } \\
\text { setelah } \\
\text { ekstraksi } \\
\text { (ppm) }\end{array}$ & $\begin{array}{l}\text { Pb yang } \\
\text { terekstrak(mg } \\
\text { /g) }\end{array}$ \\
\hline 1. & 0 & 245 & 2,23 & 99,09 & 524,50 \\
2. & 50 & 245 & 3,73 & 98,48 & 521,26 \\
3. & 100 & 245 & 4,49 & 98,17 & 519,62 \\
4. & 150 & 245 & 4,85 & 98,02 & 518,84 \\
5. & 200 & 245 & 4,32 & 98,23 & 519,98 \\
6 & 250 & 245 & 5,10 & 97,92 & 518,30 \\
\hline
\end{tabular}

Berdasarkan data di atas, dapat terlihat bahwa persen ekstraksi $\mathrm{Pb}(\mathrm{II})$ sebelum penambahan logam $\mathrm{Cu}(\mathrm{II})$ adalah $99,09 \%$. Setelah penambahan logam $\mathrm{Cu}(\mathrm{II})$ sampai dengan konsentrasi $250 \mathrm{ppm}$ persen ekstraksi logam $\mathrm{Pb}(\mathrm{II})$ adalah $97,92 \%$ dan dapat diketahui bahwa penambahan konsentrasi logam $\mathrm{Cu}(\mathrm{II})$ tidak memberikan pengaruh yang besar terhadap persen ekstraksi ion $\mathrm{Pb}$

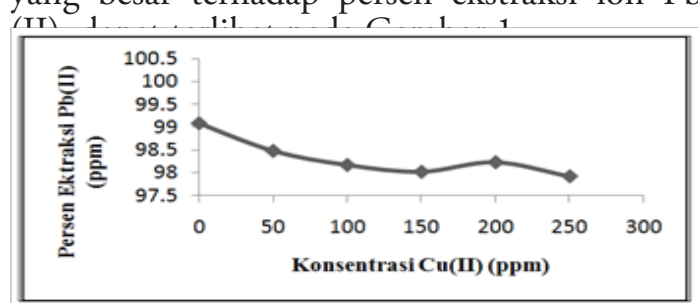

Gambar 1. Pengaruh Penambahan Konsentrasi Logam Cu(II) Terhadap Persen Ekstraksi $\mathrm{Pb}(\mathrm{II})$
Berdasarkan pada Gambar 1 untuk penambahan $\mathrm{Cu}$ (II) pada konsentrasi 200 ppm persen ekstraksi $\mathrm{Pb}$ (II) meningkat kembali. Hal tersebut dapat terjadi karena beberapa pengaruh salah satu diantaranya adalah pengaruh arus listrik yang digunakan pada alat spektrodirect yang menyebabkan hasil pengukuran absorbansi sedikit menyimpang dari hasil yang diharapkan. Karena penambahan konsentrasi logam $\mathrm{Cu}(\mathrm{II})$ yang semakin besar seharusnya akan mengurangi persen ekstraksi $\mathrm{Pb}(\mathrm{II})$.

Beberapa faktor yang dapat menyebabkan keberadaan logam $\mathrm{Cu}(\mathrm{II})$ relatif kecil mempengaruhi persen ekstraksi $\mathrm{Pb}(\mathrm{II})$ dalam proses mekanisme transfer $\mathrm{Pb}$ (II) dari fasa eksternal ke fasa internal antara lain : peningkatan $\mathrm{pH}$ larutan fasa eksternal, konsentrasi surfaktan yang digunakan dan konsentrasi asam pada fasa internal.

Penelitian ini menggunakan $\mathrm{pH}$ larutan pada fasa eksternal yaitu $\mathrm{pH} \quad 2,0$ yang berdasarkan pada penelitian terdahulu oleh Masgul (2014) yang merupakan kondisi optimum dari ekstraksi $\mathrm{Pb}$ (II) menggunakan teknik emulsi membran cair. Sedangkan, untuk $\mathrm{Cu}(\mathrm{II})$ berdasarkan penelitian yang telah dilakukan oleh Sukmawati (2007) menyatakan bahwa dengan menggunakan $\mathrm{pH} 3$ harga persen (\%) $\mathrm{E}$ maksimum $\mathrm{Cu}(\mathrm{II})$ adalah 98,65\%. Peningkatan $\mathrm{pH}$ larutan menyebabkan jumlah ion $\mathrm{OH}^{-}$semakin banyak sehingga akan terjadi kompetisi antara $\mathrm{OH}^{-}$dengan ligan untuk berikatan dengan ion logam, akibatnya jumlah ion $\mathrm{Cu}^{2+}$ yang dapat membentuk kompleks semakin berkurang.

Setiap logam memiliki kondisi optimum yang berbeda-beda. Sama halnya dengan logam $\mathrm{Cu}$ (II) dan $\mathrm{Pb}$ (II). Untuk pengaruh konsentrasi surfaktan yang digunakan, surfaktan yang digunakan pada penelitian ini adalah Span-80 dengan konsentrasi 3\%. Hal ini didasarkan pada penelitian sebelumnya oleh Masgul (2014)bahwa konsentrasi surfaktan span-80 yang menghasilkan persen ekstraksi terbesar yaitu pada konsentrasi 3\%. Konsentrasi surfaktan yang digunakan pada penelitian ini merupakan konsentrasi surfaktan berdasarkan kondisi optimum logam $\mathrm{Pb}(\mathrm{II})$. Sedangkan untuk logam $\mathrm{Cu}(\mathrm{II})$ berdasarkan penelitian yang telah dilakukan oleh Hamzah (2010) menggunakan kerosen yang mempunyai HLB butuh sebesar 6,0. Untuk memperoleh emulsi yang lebihstabil sebaiknya digunakan surfaktan lain yang memiliki HLB 6,0 atau menggunakan kombinasi surfaktan span80 dan span-20 dengan perbandingan yang 
proporsional dengan konsentrasi 2\%. Sehingga dapat diketahui bahwa dari fasa membran yang digunakan untuk logam $\mathrm{Pb}(\mathrm{II})$ berupa paraffin cair dan untuk logam $\mathrm{Cu}(\mathrm{II})$ berupa kerosen dengan penggunaan surfaktan yang berbeda. Secara skematis dapat terlihat pada Gambar 2. Penggunaan Span-80 yang kurang akan menyebabkan pembentukan lapisan tipis monomolekuler tidak tersusun rapat sehingga membran emulsi tidak stabil. Penggunaan span80 5\% menunjukkan bahwa membran emulsi cair stabil selama lebih dari delapan hari. Pada keadaan ini pembentukan film pelindung fase internal cukup rapat karena jumlah molekul emulgator telah mencukupi dan pada kondisi ini pula membran akan lebih mudah untuk

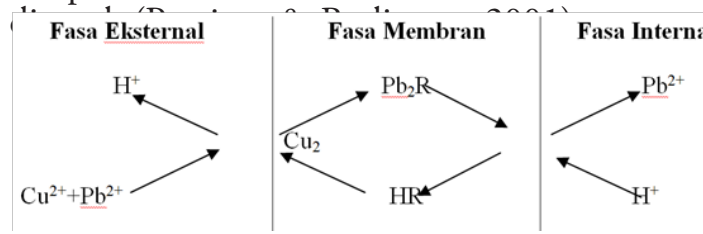

Gambar 2. Mekanisme Transfer Massa melalui Difusi denganReaksi Kimia dalam Fasa Mem bran(Hamzah, dkk., 2011)

Berdasarkan mekanisme diatas, dapat dijelaskan bahwa logam $\mathrm{Cu}(\mathrm{II})$ dan $\mathrm{Pb}$ (II) yang sebelumnya berada bersama-sama pada fasa eksternal namun, ketika akan berdifusi menuju fasa membran logam $\mathrm{Cu}$ (II) tidak dapat ikut dalam fasa membran, hal tersebut terjadi karena membran yang digunakan merupakan membran yang tidak sesuai atau tidak cocok dengan logam $\mathrm{Cu}(\mathrm{II})$ seperti yang telah dijelaskan sebelumnya. Karena membran yang digunakan tidak sesuai dengan logam $\mathrm{Cu}(\mathrm{II})$ maka khelat yang akan mengikat logam $\mathrm{Cu}$ (II) sedikit atau hampir tidak ada $\mathrm{Cu}(\mathrm{II})$ yang bisa diikat oleh khelat, sehingga semua khelat akan mengikat lebih banyak logam $\mathrm{Pb}$ (II). Maka, logam $\mathrm{Cu}$ (II) tidak dapat sampai menuju pada fasa internal. Itulah yang dapat menyebabkan logam $\mathrm{Cu}(\mathrm{II})$ tidak mempengaruhi proses mekanisme transfer $\mathrm{Pb}(\mathrm{II})$ dari fasa eksternal menuju fasa internal.

Teori HSAB (pengelompokan asam basa berdasarkan kekerasan dan kelunakan) menurut teori yang dikemukakan oleh Pearson yang menyatakan bahwa, prinsip HSAB secara kualitatif berguna, tetapi tidak secara kuantitatif memuaskan. Pearsontelah menunjukkan bahwa pencocokan keras-keras atau lembut-lembut asam dan basa merupakanstabilisasi tambahan untuk faktor-faktor lain yang berkontribusi terhadap kekuatan ikatan antara donor dana kseptor. Asam keras (kation logam keras) membentuk kompleks yang lebih stabildengan basa keras (ligan keras), sedangkan asam lunak (logam lunakkation) lebih sukadengan basa lunak (ligan lembut)(Housecroft \& Sharpe, 2005). Secara umum ion-ion logam keras (seperti logam alkali, alkali tanah, dan $\mathrm{Cr}^{3+}$ ) lebih kuat kompleksnya dengan atom donor keras (seperti O) dan ion logam lunak (seperti $\mathrm{Cd}^{2+}$ ) akan membentuk kompleks yang lebih kuat dengan atom donor lunak (seperti S) dan ion-ion logam borderline (seperti $\mathrm{Cu}^{2+}$ ) lebih kuat kompleksnya dengan atom donor borderline (seperti $\mathrm{N}$ ). Senyawa bergugus aktif atom nitrogen $(\mathrm{N})$ dan atom belerang $(\mathrm{S})$ diharapkan dapat digunakan sebagai senyawa pembawa dalam recovery logam berat, terutama $\mathrm{Cu}^{2+}$ dan $\mathrm{Cd}^{2+}$ (Djunaidi, dkk., 2010).

Berdasarkan pengelompokan asam basa menurut kekerasan dan kelunakan dapat diketahui bahwa logam $\mathrm{Cu}(\mathrm{II})$ dan $\mathrm{Pb}(\mathrm{II})$ berada pada golongan asam peralihan. Kecenderungan unsur golongan ini untuk membentuk kompleks yang lebih stabil tergantung dari bilangan oksidasinya.

Berdasarkan pada sifat kimia unsur logam $\mathrm{Cu}$ dan $\mathrm{Pb}$ dapat diketahui bahwa nilai dari sifat elektronegativitas yang dimiliki unsur tersebut sangat berbeda, unsur logam $\mathrm{Cu}$ memiliki nilai elektronegativitas 1,90 (skala pauling) sedangkan logam $\mathrm{Pb}$ 2,33 (skala pauling). Kompleks yang terbentuk dari logam dengan elektonegativitas yang tinggi akan menghasilkan kompleks yang lebih stabil, karena kecenderungan logam untuk menarik pasangan elektron yang didonasikan oleh ligan akan lebih kuat. Dalam hal yang sama, logam dengan kemampuan polarisasi yang lebih besar juga akan menghasilkan kompleks yang lebih stabil.

Konsentrasi asam pada fasa internal yang digunakan pada penelitian ini digunakan konsentrasi $3 \mathrm{M}$. Penggunaan $\mathrm{HNO}_{3} 3 \mathrm{M}$, berdasarkan pada penelitian sebelumnya oleh Astuti (2014) yang menyatakan bahwa persen ekstraksi ion logam $\mathrm{Pb}(\mathrm{II})$ terbesar ditunjukkan pada konsentrasi $\mathrm{HNO}_{3} 3 \mathrm{M}$. Sedangkan untuk logam $\mathrm{Cu}(\mathrm{II})$ berdasarkan penelitian yang dilakukan oleh Hamzah (2010) konsentrasi asam yang digunakan pada fasa internal hanya sebesar $1 \mathrm{M}$. sehingga jika menggunakan konsentrasi asam yang lebih tinggi akan lebih cepat memutuskan ikatan kelat pada logam $\mathrm{Cu}(\mathrm{II})$. Tetapi berdasarkan mekanisme pada Gambar 1 dapat terlihat bahwa logam Cu(II) tidak dapat berdifusi sampai pada fasa internal sehingga konsentrasi asam yang digunakan 
tidak berpegaruh terhadap logam $\mathrm{Cu}(\mathrm{II})$.

Penggunaan variasi konsentrasi $\mathrm{Cu}(\mathrm{II})$ bertujuan untuk mengetahui pengaruh konsetrasi $\mathrm{Cu}(\mathrm{II})$ terhadap persen ekstraksi $\mathrm{Pb}$ (II) dan digunakan variasi konsentrasi $\mathrm{Cu}$ (II) yaitu 50, 100, 150, 200 dan 250 ppm. Berdasarkan hasil analisis dengan menggunakan Spectrofotometer Spectrodirect terlihat dari Tabel 1, bahwa persen ekstraksi $\mathrm{Pb}$ tidak mengalami perubahan yang besar. Jika dilihat dari kapasitas konsentrasi $\mathrm{Pb}$ (II) yang terekstrak dengan penambahan konsentrasi logam $\mathrm{Cu}$ (II) maka danat terlihat nada Fambar 2

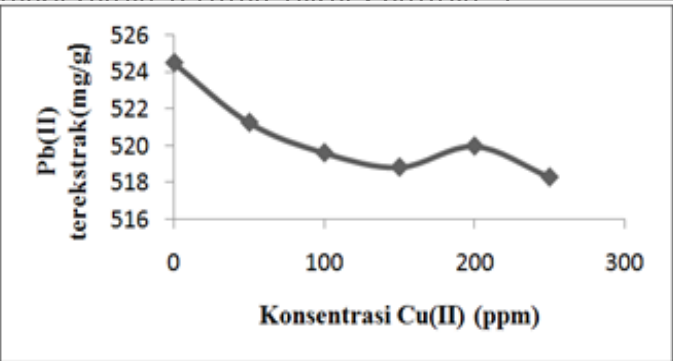

Gambar 3. Pengaruh Penambahan Konsentrasi $\mathrm{Cu}$ (II) Terhadap $\mathrm{Pb}$ (II) Terekstrak (mg/g).

Berdasarkan Gambar 3 tampak bahwa grafik antara persen ekstraksi dengan grafik kapasitas $\mathrm{Pb}(\mathrm{II})$ yang terekstrak memiliki kesamaan. Penambahan konsentrasi logam $\mathrm{Cu}(\mathrm{II})$ menyebabkan terjadinya penurunan konsentrasi $\mathrm{Pb}(\mathrm{II})$ yang terekstrak sampai pada konsentrasi $150 \mathrm{ppm}$. Namun, pada penambahan $\mathrm{Cu}$ (II) pada konsentrasi $200 \mathrm{ppm}$ $\mathrm{Pb}$ (II) yang terekstrak meningkat kembali. Hal ini terjadi karena masih terdapat ion $\mathrm{Pb}$ (II) dan $\mathrm{Cu}(\mathrm{II})$ yang belum membentuk senyawa kompleks dengan benzoil aseton. Sedangkan pada konsentrasi $250 \mathrm{ppm}$ terjadi penurunan nilai kapasitas $\mathrm{Pb}(\mathrm{II})$ yang terekstak. Hal ini disebabkan karena terjadinya kompetisi antar ligan untuk terikat pada permukaan membran dan membentuk kompleks dengan ion logam(Deswati, dkk., 2011)

\section{Kesimpulan}

Penambahan konsentrasi logam $\mathrm{Cu}(\mathrm{II})$ dengan variasi konsentrasi dari 50, 100, 150, 200 sampai dengan $250 \mathrm{ppm}$ relatif kecil dapat menurunkan persen ekstraksi $\mathrm{Pb}(\mathrm{II})$ hingga mencapai $97,92 \%$.

\section{Ucapan Terima Kasih}

Ucapan terima kasih penulis berikan kepada laboran LaboratoriumAgroteknologi Fakultas Pertanian Universitas Tadulako dan kepada laboran Laboratorium FKIP Jurusan
Pendidikan MIPA Program Studi Pendidikan Kimia Universitas Tadulako yang banyak membantu penulis dalam menyelesaikan penelitian ini.

\section{Referensi}

Alaguraj, M., Palanivelu, K. \&Velan, M. (2009). Removal of $\mathrm{Cu}(\mathrm{II})$ using emulsion liquid membrane. Journal of ChemTech Research, 1(3), 722-726.

Alam, S. (2014). Penentuan kondisi optimum ekstraksi ion timbal(II) menggunakan teknik emulsi membran cair. (Skripsi), Universitas Tadulako Palu, Tidak Diterbitkan.

Astuti, W. (2014). Variasi perbandingan fasa membrane dan fasa internal serta konsentrasi HNO3 dalam fasa internal terhadap ekstraksi ion timbal(II) menggunakan teknik emulsi membran cair. (Skripsi), Universitas Tadulako Palu, Tidak Diterbitkan.

Chang, S. H., Teng, T. T. \& Ismail, N. (2009). Optimization of $\mathrm{Cu}(\mathrm{II})$ extraction from aqueous solution by soybean-oil-based organic solvent using response surface methodology. Water Air Soil Pollut, 217(3), 567-576.

Deswati, Suryani, H. \& Pardi, H. (2011). Penentuan timbal dan tembaga dalam air laut dengan simultan menggunakan kalkon sebagai pengompleks secara voltammetri stripping adsorptif. Proseding Seminar Nasional Himpunan Kimia Indonesia

Djunaidi, M. C., Khabibi \& Trisna, D. (2010). Sintesis asam eugenoksi asetat (EOA) dari eugenoluntuk ekstraktan logam berat dan recovery krom dari limbah electroplating. Jurnal Sains Kimia dan Aplikasi, 13(2), 1-8.

Fitriya, L. (2005). Pemisahan fenol dengan teknik membran cair emulsi (ELM) menggunakan surfaktan span-80. (Skripsi), Universitas Diponegoro Semarang, Diterbitkan.

Gzar, H. A., Awatif, S., Hameed, A. \& Yahya, A. Y. (2014). Extraction of lead cadmium and nickel from contaminated soil using acetic acid. Open Journal of Soil Science, $4(1), 207-214$.

Hamzah, B. (2010). Aplikasi 1-fenil-3-metil-4benzoil-5-pirazolon sebagai pembawa kation 
pada ekstraksi ion tembaga(II) menggunakan teknik emulsi membran cair. Disertasi Doctor pada Universitas Hasanuddin Makassar, Tidak Diterbitkan

Hamzah, B., Jalaluddin, N., Wahab, A. W. \& Upe, A. (2011). Pengaruh ion kadmium(II) dan nikel(II) pada ekstraksi ion tembaga(II) dengan ekstraktan 4-benzoil -1-fenil-3metil- 2-pirazolin-5-on menggunakan emulsi membran cair. Jurnal Natur Indonesia., 13(3), 269-275.

Hamzah, B., Pulukadang, S. H. V. \& Hardani, R. (2013). Sintesis ekstraktan turunan pirazolon dan uji kestabilan emulsi untuk ekstraksi ion raksa(II) menggunakan teknik emulsi membran cair. Prosiding Seminar Nasional Sains dan Matematika II Jurusan Pendidikan MIPA FKIP UNTAD 2013.

Herlina, L. \& Wulandari, M. (2012). Penetuan timbal(II) dalam sampel air dengan pengembagan metode ekstraksi fasa padat dan prakonsentrasi oleh ion imprinted polymers(IIPs). Jurnal Teknobiologi, 3(2), 127-133.

Housecroft, C. E. \& Sharpe, A. G. (2005). Inorganic chemistry. England: Pearson
Education Limited.

Masgul, S. (2014). Pengaruh konsentrasi surfaktan (span-80) dan $p H$ fasa eksternal terhadap persen ekstraksi ion timbal(II) menggunakan teknik emulsi membran cair. (Skripsi), Universitas Tadulako Palu, Tidak Diterbitkan.

Mohamed, Y. T. \& Ibrahim, A. H. (2012). Extraction of copper from waste solution using liquid emulsion membrane. Journal of Environmental Protection, 3(1), 129-134.

Prayitno \& Budiyono, M. E. (2001). Penurunan kadar tembaga dalam air limbah dengan proses ekstraksi membran cair. Prosiding P3TM-BATAN Yogyakarta.

Rusdianasari \& Buchari. (2001). Ekstraksi uranium dari limbah cair artifisial dengan teknik membran cair aliran kontinyu. Risalah Pertemuan ilmiah Penelitian dan Pengembangan Aplikasi Isotop dan Radiasi.

Sukmawati, D. (2007). Ekstraksi Cu ${ }^{2+}$ menggunakan metode transport membran cair dengan pembentukan kompleks $\mathrm{Cu}$ oksinat. (Skripsi), Universitas Sebelas Maret 